\title{
POR QUE 0 HEDGING PARCIAL É ÓTIMO?
}

\author{
Richard Saito \\ FGV-EAESP \\ E-mail: richard.saito@fgv.br \\ Rafael F. Schiozer \\ FGV-EAESP \\ E-mail: rafael.schiozer@fgv.br
}

\section{INTRODUÇÃO}

A estratégia financeira de uma empresa envolve decisões acerca de três questões fundamentais: investimento, financiamento e gestão de riscos. Num mercado sem imperfeições (i.e., assimetria informacional, impostos, custos de falência, transação e agência), as decisões de financiamento e investimento são independentes entre si, e a gestão de riscos é incapaz de gerar valor para um acionista diversificado. Jensen e Meckling (1976), Myers (1977), e Myers e Majluf (1984), entre outros, tratam da interdependência entre as decisões de financiamento e investimento, a partir de imperfeições de mercado, como os custos de agência, custos de falência e assimetria informacional, respectivamente.

A literatura sobre a gestão de riscos corporativos ganhou espaço nos principais periódicos de Finanças a partir dos trabalhos clássicos de Stulz (1984) e Smith e Stulz (1985), que traziam as razões teóricas para que a gestão de risco pudesse gerar valor na presença de imperfeições de mercado, como função tributária convexa, custos de falência e dificuldades financeiras. $\mathrm{O}$ artigo de Froot, Scharfstein e Stein (1993), doravante Froot et al., no entanto, é o primeiro a inter-relacionar as decisões de investimento, financiamento e gestão de risco de maneira simultânea. Enquanto quase toda a literatura até então focava as práticas de hedge e precificação dos instrumentos de proteção contra riscos [o que Froot et al. (1993) chamam de "mecânica de hedge"], Froot et al. (1993) abordam os tipos de risco que a firma deve mitigar e a proporção da exposição a ser protegida. Assim, é o primeiro trabalho teórico a explicar por que o hedge parcial pode ser ótimo.

O artigo empírico de Tufano (1996), usando uma amostra de empresas do setor de mineração de ouro, mostra que as práticas de gestão de risco nas empresas estão mais ligadas à aversão ao risco de seus gestores do que a princípios de maximização do valor da empresa. Dessa forma, os conflitos de agência são apresentados como explicação complementar à teoria de Froot et al. (1993) para a existência de hedge parcial das exposições. A maior contribuição do trabalho de Tufano, no entanto, está provavelmente na metodologia desenvolvida para medir a magnitude da gestão de riscos, como será visto adiante. Sua maneira de estimar a magnitude da gestão de risco permitiu que os trabalhos empíricos futuros pudessem trabalhar não apenas com uma variável binária, que indicava a existência ou inexistência de uso de derivativos ou práticas de hedge (que era o caso da quase totalidade dos trabalhos empíricos sobre o assunto, e.g., Nance et al., 1993 e Gèczy et al., 1997), mas também com uma variável que pudesse medir consistentemente a intensidade da gestão de risco, proporcionando a possibilidade de investigações acerca da magnitude da gestão, com destaque para Graham e Smith (1999), Allayannis e Ofek (2001), e Graham e Rogers (2002). 


\section{O MODELO DE FROOT, SCHARFSTEIN E STEIN (1993) E SUA CONTRIBUIÇÃO PARA A LITERATURA}

O modelo inicial considera uma firma que enfrenta uma decisão de financiamento/investimento em dois períodos. O produto do investimento é uma função crescente e côncava do valor investido I (ou seja, há rendimentos decrescentes de escala). Sem imperfeições de mercado, a decisão ótima de investimento $I^{*}$ é aquela em que seu retorno marginal é zero. A quantidade de ativos líquidos disponíveis para investimento no primeiro período é uma variável aleatória $w$. Nesse caso, se $w<I^{*}$, a firma precisará levantar recursos externos. A taxa de desconto é fixada em zero (o que é equivalente a trabalhar com fluxos de caixa descontados à taxa ajustada pelo risco de mercado).

No primeiro caso estudado, o nível ótimo de investimentos é independente do resultado revelado de $w$ (ou seja, o conjunto de projetos com VPL positivo é o mesmo, independentemente do estado da natureza que ocorrer). Os custos de financiamento são $C$ por dólar levantado acima da taxa ajustada ao risco. Esses custos podem ser derivados de custos de falência ou dificuldades financeiras, de problemas de sub e sobre-investimento decritos por Myers (1977) ou de assimetria de informação entre insiders e outsiders. Assume-se que $C$ seja uma função crescente e convexa do capital a ser levantado externamente (a lógica para tal é consistente com o arcabouço teórico de Diamond, 1984). Nessa situação, assume-se que $w$ possa ser perfeitamente passível de hedge sem custo (ou seja, é possível trocar a variável aleatória $w$ por seu valor esperado $E[w]$ ). O problema encontrado pelo decisor é encontrar o nível de investimento ótimo $I^{*}$ que maximize o valor líquido do investimento. A condição de primeira ordem é, portanto, que o retorno marginal do investimento menos o custo marginal de levanter recursos seja igual a 1 . Obviamente, o nível ótimo de investimentos será inferior à solução ótima caso o financiamento externo não tenha custo superior aos recursos gerados internamente.

A partir de deduções matemáticas simples, fica claro que o lucro $P$ é uma função crescente e côncava da variável aleatória $w$. Da propriedade de concavidade, deduz-se que o lucro será maior se pudermos trocar a variável $w$ por seu valor esperado $E[w]$. Assim, a gestão de riscos é capaz de criar valor. Tal resultado decorre das duas pressuposições básicas: 1) o retorno marginal dos investimentos é decrescente; 2) o custo dos recursos externos é uma função crescente do volume de recursos captados externamente. Obviamente, os dois efeitos combinados produzem um efeito ainda maior na concavidade de $P(w)$.
O segundo caso analisado considera que o conjunto de oportunidades de investimento com VPL positivo não é mais independente da realização de $w$. A parcela de $w$ passível de hedge é chamada de $\epsilon$ e a correlação entre as oportunidades de investimento e $\epsilon$ é $\alpha$. Nesse contexto, o problema de maximização leva à solução simples de que a razão ótima de hedge é aquela que faz a correlação entre $P$ e $C$ ser igual a zero. Ao assumir que que $C$ e tem uma distribuição definida apenas por seu primeiro segundo momento (o que é o caso de distribuições normal, lognormal, uniforme, triangular, etc), uma expansão de Taylor leva a uma razão ótima de hedge que é uma função crescente de $\alpha$. A intuição por trás desse resultado é imediata: se as oportunidades de investimento e os fundos gerados internamente são positivamente correlacionados, a existência de fundos gerados internamente para investimentos está naturalmente garantida, e há menos necessidade de se fazer hedge $e^{1}$. Se a correlação for zero, retorna-se ao primeiro caso, e o hedge total será a solução ótima. Nos casos em que as oportunidades de investimento são extremamente sensíveis à fonte de risco, a empresa pode ter razão de hedge negativa (isto é, aumentar sua exposição ao fator de risco). Por outro lado, se $\alpha$ é negativo, passa a fazer sentido uma proteção de mais de $100 \%$, de forma a assegurar mais caixa nos estados em que $\epsilon$ esteja no lado desfavorável da distribuição de probabilidades.

Os demais casos analisados são derivações do primeiro e segundo casos aqui descritos, correlacionando o custo de financiamento externo à geração de caixa e analisando uma empresa que importa insumos e exporta produtos, com solução ótima também levando ao hedge parcial.

A parte final do artigo propõe uma série de hipóteses empiricamente testáveis derivadas da teoria apresentada. Empresas com maior grau de assimetria de informação, menor cobertura de juros e menos ativos tangíveis teriam maior propensão a fazer proteção contra riscos. Se forem usadas as despesas com $\mathrm{P} \& \mathrm{D}$ para se medir o grau de assimetria de informação (uma vez que é mais difícil estimar a qualidade de investimentos de alta tecnologia ou muito dependentes de $P \& D$ ), espera-se uma relação positiva entre $\mathrm{P} \& \mathrm{D}$ e hedge.

\section{TUFANO: A GESTÃO DE RISCO E OS CONFLITOS DE AGÊNCIA}

Desde o início dos anos 1980, diversos papers investigaram por que as empresas fazem hedge, e se a gestão de risco adiciona valor. Até a metade da década de 1990, no entanto, os trabalhos empíricos limitavam-se a investi- 
gar a gestão de risco com base em variáveis binárias que indicavam se determinada firma fazia ou não uso de derivativos financeiros. ${ }^{2} \mathrm{O}$ paper de Tufano foi o primeiro a utilizar uma medida da magnitude real das atividades relacionadas à modificação de risco, o peracionalizada pelo delta do portfólio de derivativos relacionados ao preço do ouro para uma amostra de empresas de mineração de ouro. Assim, enquanto os trabalhos anteriores não eram capazes de distinguir o uso de derivativos da real modificação de risco, Tufano não só faz essa distinção clara, como também é capaz de medir a capacidade de modificação de risco da carteira de derivativos em poder das empresas, o que é fundamental para entender a importância econômica da atividade de gestão de riscos.

Nos modelos de regressão utilizados por Tufano, a variável dependente (delta \%) é definida como o delta do portfólio de derivativos relacionados a ouro (medido em peso de ouro) dividido pela expectativa de produção nos três anos da amostra (1991 a 1993). Para calcular o delta do portfólio de derivativos (que é economicamente equivalente a uma posição vendida em ouro), Tufano recorre a dados voluntariamente divulgados pelas mineradoras de ouro, contendo informações exatas sobre as carteiras de derivativos das empresas. As regressões testam como potenciais explicadoras da gestão de risco três variáveis associadas à maximização de valor (ganhos tributários, dificuldades financeiras e oportunidades de investimento), além das variáveis ligadas à aversão do gestor ao risco.

Os resultados mostram que há pouco suporte empírico indicando que a gestão de risco seja explicada pelas hipóteses de maximização de valor ao acionista. Por outro lado, os resultados indicam claramente que a gestão de risco está ligada à maximização da utilidade dos gestores. Mostra-se que as firmas cujos gestores possuem mais ações tendem a fazer mais gestão do risco, enquanto aquelas cujos gestores detêm mais opções fazem menos gestão de risco. Esse resultado é consistente quando se considera a diretoria como um todo, apenas o CEO ou apenas o CFO individualmente. Outro resultado que corrobora a relação entre gestão de riscos e maximização de utilidade dos gestores é que, nas firmas em que há blocos de controle dos quais os gestores não fazem parte, verifica-se atividade menos intensa de gestão de risco, ao passo que nas empresas cujos gestores petencem ao bloco de controle faz-se mais gestão de risco.

É importante notar que pode haver uma relação endógena entre a posse de ações e opções e a gestão de risco. Nas firmas que fazem gestão de risco, os diretores podem escolher serem remunerados com ações, ao passo que os gestores podem preferir opções nas firmas que fazem pou- ca gestão de risco. Outro resultado interessante é que a gestão de risco está negativamente relacionada ao tempo no cargo do chief financial officer (CFO). Tufano oferece duas possíveis explicações para o fato: i) empresas que desejam fazer gestão de risco contratam CFOs mais jovens; ii) a remuneração dos gestores constitui uma parcela mais importante da riqueza para os gestores mais jovens do que para os mais velhos.

\section{CONCLUSÕES}

Até o final da década de 1980, a teoria de finanças corporativas havia construído bases sólidas para explicar as inter-relações entre as decisões de financiamento e investimento, em face de uma série de imperfeições de mercado, como conflitos de agência, assimetria informacional, custos de falência e dificuldades financeiras. No entanto, havia uma lacuna no que se refere ao papel da gestão de riscos e sua relação com as decisões de investimento e financiamento. Os dois papers analisados neste texto trazem contribuições fundamentais para uma melhor compreensão da complexa função da gestão de riscos. O artigo de Froot, Scharfstein e Stein (1993) encontra na relação hedge-financiamento-investimento a explicação teórica completa que preenche uma importante lacuna na teoria de finanças: a explicação da proteção parcial como decisão ótima para a maximização do valor da empresa, a partir de custos de financiamento externo. Já o artigo empírico de Tufano encontra empiricamente nos conflitos de agência - como, por exemplo, a tendência de maximização da utilidade do gestor - uma importante explicação para a gestão de riscos. Mais importante, a metodologia usada por Tufano permitiu que se medisse de forma consistente o tamanho da exposição gerada, isto é, a modificação efetiva de risco advinda das atividades de hedge, embora para uma amostra reduzida e segmentada de empresas mineradoras de ouro nos EUA.

Nos EUA, após as instruções SFAS (Statement of Financial Accounting Standards) número 119 e 133, no final da década de 1990, as carteiras de derivativos passaram a ser divulgadas nos relatórios que as empresas devem enviar regularmente à Securities and Exchange Comission (SEC) e aos investidores. Isso impulsionou a pesquisa em gestão de riscos, e diversos trabalhos passaram a utilizar a metodologia de Tufano (com adaptações ou modificações) para estimar a magnitude da gestão de risco sendo gerenciada com derivativos para uma gama ampla de empresas nos diversos setores da economia nos EUA. Artigos de grande relevância para a literatura de ges- 
tão de riscos corporativos, como os de Allayanis e Weston (2001), Graham e Rogers (2002), Allayanis e Ofek (2001), e Guay e Kothari (2003), usam versões modificadas da metodologia de Tufano, o que ratifica a importância desse trabalho seminal.

No Brasil, infelizmente, o disclosure por parte das empresas dos contratos de derivativos ainda não está completamente normatizado, o que causa uma não-uniformidade nos demonstrativos contábeis, dificultando a realização de pesquisas na área. Trabalhos empíricos sobre a gestão de risco corporativo no Brasil têm se limitado a pesquisas a partir de dados não públicos, como Oliveira e Novaes Filho (2005), que utilizam uma base de dados privada do Banco Central do Brasil, e Schiozer e Saito (2007), que estudam exclusivamente empresas com ADRs, um subconjunto de firmas com características específicas dentro do universo de empresas brasileiras. A investigação empírica sobre gestão de riscos em mercados emergentes possui um enorme potencial, uma vez que as economias emergentes apresentam características bastante distintas da dos EUA, onde se desenvolveu a maior parte da literatura de gestão de riscos até hoje. As economias emergentes são, em geral, mais susceptíveis a eventos político-institucionais e ao contágio de crises externas, apresentando maior volatilidade em suas taxas de juros e câmbio.

Com o crescente esforço institucional por um maior desenvolvimento dos mercados financeiros e de capitais no Brasil, em especial com as questões relacionadas à governança corporativa, o que passa por uma maior transparência na divulgação das atividades financeiras das empresas, num futuro muito próximo talvez seja possível obter dados para pesquisas brasileiras de qualidade comparável à internacional.

\section{NOTAS}

1. O caso em que as oportunidades de investimento se relacionam positivamente com o fator de risco w é extremamente plausível economicamente. O nível ótimo de investimentos de uma firma exportadora, por exemplo, é tanto maior quanto mais desvalorizada esteja a moeda local. Da mesma forma, um produtor de commodities deve investir mais quando o preço de seu produto assumir valores elevados.

2. Em geral a variável dependente que indicava a gestão dos riscos era o uso de derivativos financeiros, como contratos futuros, a termo, opções e swaps. Assim, essa variável binária recebia valor 1 caso a empresa utilizasse pelo menos um desses tipos de contrato e 0 caso contrário. Esa definição de gestão do risco foi utilizada por diversos autores em artigos, entre eles Nance et al. (1993), Gèczy e Minton (1995) e outros.

\section{REFERÊNCIAS}

ALLAYANNIS, G., OFEK, E., Exchange rate exposure, hedging, and the use of foreign currency derivatives. Journal of International Money and Finance, v. 20, n. 2, p. 273-296, 2001.

ALLAYANNIS, G., WESTON, J. P., The use of foreign currency derivatives and firm market value. Review of Financial Studies, v. 14, n. 1, p. 243-276, 2001

DIAMOND, D. W., Financial intermediation and delegated monitoring Review of Economic Studies, v. 51, n. 3, p. 393-414, 1984

FROOT, K. A., SCHARFSTEIN, D. S., STEIN, J. C., Risk management, coordinating investment and financing policies. Journal of Finance, v. 48, n. 5 , p. $1629-1658,1993$

GĖCZY, C., MINTON, B., SCHRAND, C., Why firms use currency derivatives. Journal of Finance, v. 52, n. 4, p. 1323-1354, 1997.

GRAHAM, J. R., ROGERS, D. A. Do firms hedge in response to tax incentives? Journal of Finance, v. 57, n. 2, p. 815-839, 2002.

GRAHAM, J. R.; SMITH, C. W. Tax incentives to hedge. Journal of Finance, v. 54 , n. 6 , p. 2241-2262, 1999

GUAY, W; KOTHARI, S. P. How much do firms hedge with derivatives? Journal of Financial Economics, v. 70, n. 3, p. 423-461, 2003

JENSEN, M. C.; MECKLING, W. H. Theory of the firm, managerial behavior, agency costs, and ownership structure. Journal of Financial Economics, v. 3 , n. 4 , p. $305-60,1976$

MYERS, S. C. Determinants of corporate borrowing. Journal of Financial Economics, v. 5, n. 1, p. 147-176, 1977

MYERS, S.C.; MAJLUF, N. S. Corporate financing and investment decisions when firms have information that investors do not have. Journal of Financial Economics, v. 13, n. 1, p. 187-221, 1984.

NANCE, D. R.; SMITH, C. W.; SMITHSON, C. W. On the determinants of corporate hedging, Journal of Finance, v. 48, n. 1, p. 267-284, 1993.

OLIVEIRA, F. N.; NOVAES FILHO, W. Demanda de Derivativos de Câmbio no Brasil: Hedge ou Especulação? In: ENCONTRO DA SOCIEDADE BRASILEIRA DE FINANÇAS, 5., 2005, Vitória. Anais... Vitória: SBFIN 2005

SCHIOZER, R. F; SAITO, R. The determinants of corporate risk management in Latin America. Emerging Markets Finance and Trade, 2008, no prelo.

SMITH, C. W, STULZ, R. M. The determinants of firms' hedging policies. Journal of Financial and Quantitative Analysis, v. 20, n. 4, p. 391$405,1985$.

STULZ, R. M. Optimal hedging policies. Journal of Financial and Quantitative Analysis, v. 19, n. 2, p. 127-140, 1984.

TUFANO, P. Who manages risk? Journal of Finance, v. 51, n. 4, p. $1097-$ $1137,1996$. 